\title{
Food Decision-Making: Effects of Weight Status and Age
}

\author{
Floor van Meer $^{1} \cdot$ Lisette Charbonnier $^{1}$ • Paul A. M. Smeets ${ }^{1,2}$
}

Published online: 29 July 2016

(C) The Author(s) 2016. This article is published with open access at Springerlink.com

\begin{abstract}
Food decisions determine energy intake. Since overconsumption is the main driver of obesity, the effects of weight status on food decision-making are of increasing interest. An additional factor of interest is age, given the rise in childhood obesity, weight gain with aging, and the increased chance of type 2 diabetes in the elderly. The effects of weight status and age on food preference, food cue sensitivity, and self-control are discussed, as these are important components of food decision-making. Furthermore, the neural correlates of food anticipation and choice and how these are affected by weight status and age are discussed. Behavioral studies show that in particular, poor self-control may have an adverse effect on food choice in children and adults with overweight and obesity. Neuroimaging studies show that overweight and obese individuals have altered neural responses to food in brain areas related to reward, self-control, and interoception. Longitudinal studies across the lifespan will be invaluable to unravel the causal factors driving (changes in) food choice, overconsumption, and weight gain.
\end{abstract}

This article is part of the Topical Collection on Obesity

Paul A. M. Smeets

p.smeets@umcutrecht.nl

Floor van Meer

floor@isi.uu.nl

Lisette Charbonnier

lisette@isi.uu.nl

1 Image Sciences Institute, Brain Center Rudolf Magnus, University Medical Center Utrecht, room Q02.445, Heidelberglaan 100, 3584 CX Utrecht, The Netherlands

2 Division of Human Nutrition, Wageningen University \& Research Centre (Bode 62), 8129, 6700 EV Wageningen, The Netherlands
Keywords Food choice $\cdot$ Decision-making · Obesity · Development $\cdot$ Neural correlates

\section{Introduction}

People make over 200 food decisions per day [1]. Food decisions are the choices made concerning what, when, and how much to eat. Together, they determine energy and nutrient intake. When more energy is consumed than is expended, e.g., by eating energy-dense fast foods, overconsumption occurs. Since overconsumption causes a positive energy balance, which leads to weight gain, it is considered to be a main cause of obesity [2]. Rates of childhood obesity are rising at an alarming rate [3], and the chance that an obese child develops into an obese adult is much higher than that of a normal-weight child. Moreover, once people have become overweight or obese, it is quite challenging for them to revert to a stable healthy weight. Thus, prevention of overconsumption is crucial [4], and this requires knowledge on the drivers of food decision-making and how these are affected by weight status. Furthermore, since the prevalence of overweight, obesity, and type 2 diabetes increases with age, determinants of food decisions in older adults are of vital importance as well. Although food choices are affected by many factors, such as availability, cultural, economic, and ethical considerations, this review focuses on the effects of weight status and age, as two key characteristics. To give a comprehensive overview of how weight status and age influence food decision-making, both behavioral and neuroscience studies will be discussed (Fig. 1). We aim to provide an understanding of the causes of maladaptive food decisions and identify knowledge gaps and new avenues for possible interventions. 


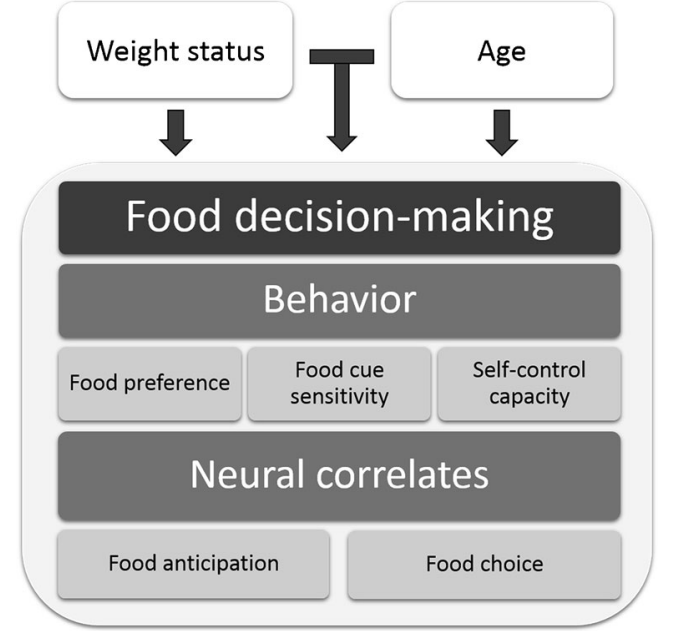

Fig. 1 Schematic overview of the factors affecting food decision-making which are discussed in this review. Note that external factors are outside the scope. The effects of weight status and age on factors examined in behavioral studies (food preference, food cue sensitivity, and self-control capacity) and factors examined in neuroimaging studies (food anticipation and food choice) are shown in the order in which they are discussed in the text

\section{Food Choice Behavior}

There are many models of food choice, ranging from sociopsychological and cultural models to economic models. Food choice behavior has been studied with many research methodologies, such as qualitative measures, food frequency questionnaires, food choice tasks, intake measurements, eye-tracking, and measurements of purchase. We grouped the literature into three topics that are relevant for understanding the role of weight status and age in food choice behavior: food preference, food cue sensitivity, and self-control capacity (Fig. 1, Table 1).

\section{Food Preference}

Nutrient and energy rich foods appear to be naturally attractive to all humans [5]. Food preferences are largely learned by experience; only sweet taste preference is inborn [6]. It has been hypothesized that an innate preference for energy-dense foods leads to higher consumption of these foods and thus

Table 1 Key influencers of food decision-making and the strength of evidence for effects of weight status and age

\begin{tabular}{llc}
\hline & Weight status & Age \\
\hline Food preference & \pm & + \\
Food cue sensitivity & \pm & + \\
Self-control capacity & + & + \\
\hline
\end{tabular}

+ denotes factor has been shown to have an effect. \pm denotes evidence for this factor having an effect is conditional or inconclusive obesity [7]. However, overweight and obese individuals do not give higher preference ratings when tasting food (both high and low energy) than normal-weight individuals [8]. Furthermore, in both children and adults, there is no clear evidence for a relationship between taste sensitivity or preference for sweet, salty, sour or bitter tastes, and weight status [9•] (review in which studies that use taste sensitivity, taste preference, and hedonic preference measures were included). There is some evidence for a higher preference for fatty foods in overweight and obese individuals and higher preference for salty foods in overweight and obese children [9•]. Taken together, it is more likely that obesity is related to problems in dealing with food cues and the motivation to eat, than with heightened pleasure derived from eating or a stronger preference for energy-dense foods [7, 9•].

Children's food preferences are highly determined by their experiences with the food and the preferences of their parents [10]. Repeatedly exposing children to foods, for example green vegetable soup, increases preference and consumption [11]. Unfortunately, children are often exposed to advertisements for unhealthy snack foods, e.g. on television, which increases their preference for foods high in fat, sugar, and salt [12]. Children's initial preferences last throughout adolescence, but may change as they eat more meals outside their home [13]. Elderly people experience loss of appetite associated with aging and a functional decline of taste and smell that may lead to decreases in food palatability [14] and may change their food choices towards more intense flavors [15]. In conclusion, higher preference for fat may be linked to overweight, but evidence for this is marginal. Although food preferences change over the lifespan, there are no studies showing that this leads to a changed risk of overconsumption.

\section{Food Cue Sensitivity}

Food cues are relevant for everyone from a biological perspective. In line with this, hungry normal-weight individuals have an attentional bias towards food cues (using a dot probe task [16] with food-related words), since these are then more relevant [17]. When sated, normal-weight subjects have a diminished attentional bias towards food cues, while overweight women have been found to exhibit greater attention for food compared to non-food cues when satiated, as measured with eye-tracking during visual probe tasks (based on [16] but using pictures instead of words) [18, 19]. A similar study did not find such differences between hungry and satiated women or weight groups in a viewing task showing pictures of objects compared with pictures of high energy foods. In a dot probe task done in the same individuals however, overweight and obese individuals did automatically direct their attention to food-related stimuli to a greater extent than normal-weight individuals, in particular when hungry [5]. 
Although overweight children may have a higher food cue sensitivity than normal-weight children (as shown by their performance on a Stroop task [20] using food-related words [21]), it may be the case that all children have an attentional bias towards palatable foods when measured with an imbedded word test [22] and a visual probe task [23, 24]. When comparing children to adults, adults are initially strongly attracted by unhealthy foods, but they shift their attention from the unhealthy to the healthy foods, suggesting a selfregulation process of avoidance when measured in with naturalistic viewing paradigm [25]. Children, on the contrary, attend more strongly to unhealthy foods and do not shift their attention away [26]. In older adults and elderly, food cue sensitivity has not been studied. In summary, overweight individuals may be more sensitive to food cues, and hunger status likely plays a role in the differences in study outcomes. Children may have a bias towards (palatable) unhealthy food and find it hard to direct their attention away from it.

\section{Self-Control Capacity}

The ability to regulate behavior effectively is relevant in many aspects of daily life, such as the consumption of healthy food, purchase decisions, or sexual behavior. Self-control refers to the ability to withhold a response with an immediately rewarding outcome in favor of a response with an outcome that is more advantageous in the long run. Thus, self-control is an important part of healthy food choice, as a lack of it may result in unhealthy food choices and overconsumption. In line with this, self-control capacity has been shown to be negatively related with body weight $[27,28]$.

In adults, obesity is associated with impaired response inhibition capacity, greater delay discounting, and reduced executive function in general [28-30]. Response inhibition refers to suppression of actions that are inappropriate in a given context and that interfere with goal-driven behavior [31]. Response inhibition is most often measured with go/no-go and stop-signal tasks (e.g., [32, 33]). Delay discounting refers to the tendency for more remote outcomes to have less value [34]. This is often measured with a delay discounting task, in which a choice has to be made between an amount of money available immediately or a larger amount of money available later. In children, delay of gratification has been measured with tasks in which they are asked to resist a small reward (e.g., a marshmallow) for $15 \mathrm{~min}$ in favor of multiple or greater rewards later [35]. Executive functioning is an umbrella term that includes cognitive control, the ability to sustain or flexibly redirect attention, the inhibition of inappropriate behavioral responses, initiation and execution of strategies, and the ability to flexibly switch among strategies [36]. All of these constructs contribute to self-control ability. In children, self-control improves as they grow older. Accordingly, children and adolescents are more impulsive than adults, as is apparent from both response inhibition tasks and choice impulsivity tasks (such as delay of gratification and delay discounting) [37••]. However, the relative level of selfcontrol at a given age is a stable personality trait. In accordance with findings in adults, there is a consistent relationship between self-control and weight status in children. Overweight and obese children and adolescents exhibit reduced executive function [38, 39], and less cognitive flexibility as measured with the Wisconsin Card Sorting Test (WCST) [40]. In line with this, a delay of gratification task at preschool age even predicts BMI 30 years later [41]. As adults age, self-control may improve as they become less impulsive and delay discounting tendencies decline [42]. To conclude, weight status and age are both related to self-control; and because of its stability over time and predictive value for weight status, further research on self-control mechanisms in food choice and how to increase self-regulatory success.

For a summary of the behavioral results see Table 1 . In the field of food decision-making, older adults and elderly have not been the subject of many studies. Thus, it remains unclear which factors influence food choices later in life.

\section{Neural Correlates of Food Decision-Making}

Food choices are made in the brain, integrating a multitude of neural and hormonal signals reflecting internal state and the environment [43]. The brain does not reach full maturity until 21 years of age. Furthermore, not all brain areas mature at the same rate; relatively greater changes have been reported in the prefrontal cortex (PFC) compared with the other brain regions between the age of 8 and the early 20s for synaptogenesis [44], gray matter reduction [45], myelination increase [46], and resting level metabolism [47]. Areas in the PFC, such as its lateral areas, mediate the capacity to voluntarily inhibit desire for a short-term reward in favor of a (larger) longterm reward [48] and are thus important for self-control. As people grow old, there are gradual structural changes such as decreases in gray matter density and synaptic pruning and cell shrinkage [49].

How the brain reacts to food is often measured by functional magnetic resonance imaging (fMRI). The most widely used fMRI technique is blood-oxygen level-dependent (BOLD) fMRI. This form of fMRI exploits the fact that at a site of increased neuronal firing (brain activation), changes in blood oxygenation occur which lead to a small increase in the fMRI signal $(\sim 1 \%)$. Neuroimaging studies that have examined processes underlying food decision-making can be divided into two categories: anticipation to food upon cue exposure and food choice. In Table 2, an overview is given of the brain regions most commonly implicated in food anticipation and choice. 
Table 2 Brain areas most consistently implicated in studies on food anticipation and food choice

\begin{tabular}{ll}
\hline Area & Function \\
\hline $\begin{array}{l}\text { Ventromedial prefrontal cortex (vmPFC)/OFC } \\
\text { Dorsolateral prefrontal cortex (dlPFC) }\end{array}$ & $\begin{array}{l}\text { Incentive/subjective value of food } \\
\text { Self-control, anticipation of reward, monitoring } \\
\text { of behavioral consequences } \\
\text { Conflict monitoring, self-control }\end{array}$ \\
Anterior cingulate cortex (ACC) & $\begin{array}{l}\text { Emotion, assigns value to sensory stimuli (valence) } \\
\text { Amygdala }\end{array}$ \\
Episodic memory and learning aspects of food-related \\
behaviors such as dietary learning
\end{tabular}

\section{Neural Correlates of Anticipation to Food}

The process of food choice starts with the anticipation phase, when food or food-related cues are perceived or thought of. Upon perception of a food cue, multiple processes occur in the brain such as preparation for food ingestion and food evaluation $[43,50]$. Examining brain responses to food cue exposure helps to elucidate the mechanisms underlying eating behavior. This is supported by studies showing that brain reactivity to food cues predicts things like future weight gain in adolescent girls [51] and women [52], food choice [53, 54], snack consumption [55], weight status [56], and outcome in a weightloss program [57]. When normal-weight individuals look at food pictures compared with non-food pictures, areas in the appetitive brain network become active. This network centers around four interconnected brain regions: (1) the amygdala and hippocampus, (2) the orbitofrontal cortex (OFC) and ventromedial prefrontal cortex (vmPFC), (3) the striatum, and (4) the insula $[50,58]$. Furthermore, brain areas involved in attention and visual processing (lateral occipital complex) are consistently more active in response to food compared with nonfood pictures [50].

Functional neuroimaging has provided a means to investigate on a neural level whether overweight and obese individuals are more sensitive to food cues (see, e.g., Schachter's externality hypothesis, which states that obese people are more reactive to external food cues and less sensitive to internal hunger and satiety signals than normal-weight individuals [59]) and may thus exhibit greater anticipatory brain activation upon food cue exposure. Indeed, overweight and obese individuals have increased activation in response to food cues in regions associated with cognitive evaluation of salient stimuli (OFC, dorsomedial prefrontal cortex; dmPFC, anterior cingulate cortex; ACC), motor responses (precentral gyrus) and explicit memory (parahippocampal gyrus), when compared with normal-weight individuals. Additionally, they have reduced activation in regions linked to cognitive control (dorsolateral prefrontal cortex; dIPFC) and interoceptive awareness (insular cortex) compared to normal-weight individuals [60॰]. Furthermore, hunger state has a differential effect on obese than on normal-weight individuals. When hungry, obese individuals show greater activation in areas involved in emotion and memory (amygdala/hippocampus), and reduced activation in areas involved in interoception (insula) than those with normal-weight. When satiated, obese individuals have greater activation in reward areas (caudate body/striatum), areas associated with cognitive evaluation of salient stimuli (dmPFC), and attention (supramarginal gyrus) than normal-weight individuals [61]. Thus, overweight and obese individuals may have a stronger anticipatory response to food in areas involved in evaluation and memory and a lower response in areas important for cognitive control and interoception. Food-related brain responses of overweight and obese people may be differentially affected by satiation as they may have a higher reward response than normal-weight people when satiated. This may make them more likely to eat even when they are not hungry.

In response to food cues, children most consistently activate the same areas as adults do, which are part of the appetitive brain network [62•]. There are some indications that children may not activate areas important for cognitive control (ventrolateral prefrontal cortex; vlPFC), but there are not enough studies in children to properly establish this [62•]. Only a handful of studies have looked at the difference in brain activation in response to food cues between normalweight and overweight children. When comparing overweight and obese with normal-weight children, the former show higher activation during food anticipation in areas involved in cognitive control (dlPFC, vlPFC), interoception (insula), and cognitive evaluation of salient stimuli (OFC, ACC) [51, 
63-65]. Overweight and obese children deactivate areas involved in visual attention (the middle occipital and fusiform gyrus), memory (the hippocampus and parahippocampal gyrus), and reward (the caudate/striatum) compared with normal-weight children [63]. In summary, children may have less inhibitory activation during food anticipation. Few studies have been done in overweight children and results appear to contradict those in adults, as children with overweight have a higher response in areas involved in cognitive control and interoception when compared with normal-weight children while the opposite is found in adults. Intriguing as this finding may be, given the small number of studies and large age ranges of children studied (8-18 years), future studies should directly compare normal and overweight children and adults. So far, no studies have addressed the neural correlates of food anticipation in older adults or elderly.

\section{Neural Correlates of Food Choice}

To date, the neural correlates of food choice have been studied relatively little. Various tasks and designs have been used to investigate aspects of the brain processes behind food decisions. These studies mostly use single or dual food choice paradigms [53, 66-73], willingness to pay for different foods [74-77], or auction paradigms [78]. However, tasks, types of choices, stimuli, and participant characteristics vary greatly between studies. In the decision-making process, the different attributes of the stimuli (e.g., taste, healthiness, size, and packaging) are valued, weighed, and integrated into a single stimulus value $[79,80 \bullet \bullet$. Neuroimaging studies have consistently shown that this stimulus value is encoded in the vmPFC, both for food and non-food (e.g., monetary) items [70-77, 81]. For a comprehensive review on the neurocomputational perspective of dietary choice see Rangel [80••].

In the context of overconsumption, it is interesting to investigate how healthiness of food impacts the food choice process. To elucidate what happens in the brains of people motivated to make healthy choices, dieters can be examined. When dieters successfully make healthy choices, the value signal encoded in the vmPFC is increased by the healthiness of the choice option. During healthy choice, vmPFC activation is modulated by the dIPFC when self-control is necessary (e.g., when refusing an unhealthy, but tasty food) [72]. In dieters that do not successfully exercise self-control, the value signal in the vmPFC only reflects taste, while in successful self-controllers it incorporates both taste and health. Intriguingly, these neural mechanisms underlying successful self-control can be activated by merely asking people to consider the healthiness of the food. When considering healthiness, the vmPFC value signal incorporates the health aspects of the food even in individuals without an explicit health goal. Furthermore, the vmPFC signal is again modulated by the dlPFC, and they make healthier choices [73]. In everyday life, a health cue might come in the form of a health label used in marketing (such as "high in calories" or "low fat content"). When labels like this are shown alongside food in a food choice task, the healthiness of the foods is encoded in the amygdala (emotion) [66]. Interestingly, there is a negative coupling between amygdala and dIPFC when these health labels are shown [66]. The difference between the neural responses to health considerations and health labels may be caused by the fact that the health labels were shown more implicitly compared with the explicit instruction to consider healthiness. Alongside health labels, health information is commonly encountered in the shape of nutritional value tables on food packaging. However, a more graphic design, a traffic light system, has been proposed as an alternative and is more effective in promoting healthy choices [82]. When the neural responses to this traffic light label are compared with textbased nutritional information, red traffic light signaling (for unhealthy foods) activates the dlPFC, and there is increased coupling between dIPFC and vmPFC [83•].This suggests that explicitly asking to attend to healthiness or a graphic health label leads to different neural processing than implicitly showing a health label. This should however be further examined.

An interesting way to look at the effect of caloric content and tastiness of foods is to make choice-pairs based on liking. When people choose a high calorie product over a low calorie product, while they are sated and they have rated the foods as equally tasty, the superior temporal sulcus, a brain area involved in processing biological relevant information is activated [69]. This suggests that even when motivation to eat is low, the brain still tracks caloric value. Choice-pairs can furthermore be made challenging by design, by pairing a liked high calorie food with a less liked low calorie food. Weightconcerned women, who are trying to limit their energy intake but are generally unsuccessful in this, show lower activation in the anterior cingulate cortex, an area involved in valuation and conflict monitoring when making challenging choices, and accordingly fail to choose in line with their dieting goal [67].

To our knowledge, the effects of weight status or age on the neural correlates of food choice have not yet been examined. However, since the dlPFC is among the last brain regions to mature, the self-control system may be underdeveloped in children, which would make healthy food decisions more challenging for them. Furthermore, lower dlPFC activation in overweight/obese adults during food anticipation suggests that they may have poorer self-control.

In conclusion, there is a growing body of work on the neural correlates of food choice. Valuation activity in the vmPFC appears to be mostly related to tastiness in normalweight individuals. When considering the healthiness of the food, or attending to graphic health labels, health value is encoded in the dIPFC and positively modulates vmPFC activation. More implicit health information is encoded in the amygdala and negatively coupled with dlPFC activation. 
Even when satiated, the brain tracks caloric content during choice, and the lack of conflict-related brain activation may cause self-control to fail in weight-concerned women. Future studies should expand this by exploring the role of weight status and age on healthy decision-making.

\section{Discussion}

Although the obesity epidemic has caused increased attention for food decision-making, there are still several underexplored areas. Without longitudinal studies, it is impossible to establish the causality of any of the factors discussed that influence food decision-making. For example, we cannot say whether poor self-control causes weight gain or that the state of being obese causes diminished self-control. Large population-based cohorts can hopefully be used to collect valuable information on how weight gain and weight loss impact food decisionmaking. Furthermore, there is an overrepresentation of college-aged adults in the literature, little work has been done in children, and almost no work has been done in older adults and elderly, while the latter two are very important groups to target. Since an overweight child has a large chance to develop into an overweight adult, prevention of overconsumption of unhealthy foods and formation of healthy eating habits in children is crucial. Moreover, many Western countries have an increasing elderly population, and many health problems experienced by the elderly such as type 2 diabetes, cognitive decline, and cardiovascular disease have been associated with overweight/obesity and specific dietary factors, such as saturated fat intake and vitamin E and B12 deficiency [84]. Thus, additional research into food choice in older adults could be beneficial for multiple health outcomes. Lastly, the field would greatly benefit from standardization of methods, both in behavioral and neuroscience studies, to decrease between study variability and foster meta-analyses and replication studies.

\section{Conclusions}

Age and weight status both significantly influence the food decision-making process; however, more work, especially in children and elderly, is needed to better understand the drivers of dietary decision-making. Behavioral studies show that in particular poor self-control may have an adverse effect on food choice in children and in those with overweight and obesity. Neuroimaging studies show that overweight and obese individuals have different neural responses to food in the brain regions involved in reward, self-control, and interoception. More research into the neural correlates of food choice may provide better insight in the effects of age and weight on the food decision-making process and provide targets for healthy eating interventions, which may be tuned to different subgroups like children or dieters. Longitudinal studies including individuals differing in weight status will be invaluable to unravel the causal factors that shape food decisions.

Acknowledgments The authors were financially supported by the European Union Seventh Framework Programme (FP7/2007-2013) under Grant Agreements 266408 (Full4Health), 266044 (I.Family), and 607310 (Nudge-It).

\section{Compliance with Ethical Standards}

Conflict of Interest Floor van Meer, Lisette Charbonnier, and Paul A.M. Smeets declare that they have no conflict of interest.

Human and Animal Rights and Informed Consent All procedures performed in studies involving human participants were in accordance with the ethical standards of the institutional and/or national research committee and with the 1964 Helsinki declaration and its later amendments or comparable ethical standards. This article does not contain any studies with animal subjects performed by any of the authors.

Open Access This article is distributed under the terms of the Creative Commons Attribution 4.0 International License (http:// creativecommons.org/licenses/by/4.0/), which permits unrestricted use, distribution, and reproduction in any medium, provided you give appropriate credit to the original author(s) and the source, provide a link to the Creative Commons license, and indicate if changes were made.

\section{References}

Papers of particular interest, published recently, have been highlighted as:

- Of importance

•• Of major importance

1. Wansink B, Sobal J. Mindless eating: the 200 daily food decisions we overlook. Environ Behav. 2007;39:106-23. doi:10.1177/0013916506295573.

2. Blundell JE, Cooling J. Routes to obesity: phenotypes, food choices and activity. Brit J Nutr. 2000;83:S33-S8.

3. Wang Y, Lobstein TIM. Worldwide trends in childhood overweight and obesity. Int J Pediatr Obes. 2006;1:11-25. doi:10.1080/17477160600586747.

4. Styne DM. Childhood and adolescent obesity: prevalence and significance. Pediatr Clin N Am. 2001;48:823-54.

5. Nijs IM, Muris P, Euser AS, et al. Differences in attention to food and food intake between overweight/obese and normal-weight females under conditions of hunger and satiety. Appetite. 2010;54: 243-54.

6. Berridge KC. Food reward: brain substrates of wanting and liking. Neurosci Biobehav R. 1996;20:1-25.

7. Mela DJ. Determinants of food choice: relationships with obesity and weight control. Obes Res. 2001;9:249S-55S. doi:10.1038/oby.2001.127.

8. Dressler H, Smith C. Food choice, eating behavior, and food liking differs between lean/normal and overweight/obese, low-income women. Appetite. 2013;65:145-52. doi:10.1016/j.appet.2013.01.013. 
9. Cox DN, Hendrie GA, Carty D. Sensitivity, hedonics and preferences for basic tastes and fat amongst adults and children of differing weight status: a comprehensive review. Food Qual Prefer. 2016;48:359-67. doi:10.1016/j.foodqual.2015.01.006. Useful review that explores the relationship between individual responsiveness to taste stimuli and weight status.

10. Skinner JD, Carruth BR, Bounds W, et al. Children's food preferences: a longitudinal analysis. J Am Diet Assoc. 2002;102:1638-47.

11. de Wild VW, de Graaf C, Jager G. Effectiveness of flavour nutrient learning and mere exposure as mechanisms to increase toddler's intake and preference for green vegetables. Appetite. 2013;64:89-96.

12. Boyland EJ, Halford JC. Television advertising and branding. Effects on eating behaviour and food preferences in children. Appetite. 2013;62:236-41.

13. Brown K, McIlveen H, Strugnell C. Nutritional awareness and food preferences of young consumers. Nutr Food Sci. 2000;30:230-5.

14. Lumbers M, Raats M. Food choices in later life. In: Shepherd R, Raats M, editors. The psychology of food choice. Frontiers in nutritional science 3. Wallingford: CABI; 2006. p. 289.

15. Schiffman S, Graham B. Taste and smell perception affect appetite and immunity in the elderly. Eur J Clin Nutr. 2000;54:S54.

16. MacLeod C, Mathews A, Tata P. Attentional bias in emotional disorders. J Abnorm Psychol. 1986;95:15.

17. Mogg K, Bradley BP, Hyare $\mathrm{H}$, et al. Selective attention to food-related stimuli in hunger: are attentional biases specific to emotional and psychopathological states, or are they also found in normal drive states? Behav Res Ther. 1998;36:22737. doi:10.1016/S0005-7967(97)00062-4.

18. Castellanos EH, Charboneau E, Dietrich MS, et al. Obese adults have visual attention bias for food cue images: evidence for altered reward system function. Int J Obes. 2009;33:1063-73.

19. Werthmann J, Roefs A, Nederkoorn C, et al. Can(not) take my eyes off it: attention bias for food in overweight participants. Health Psychol. 2011;30:561-9. doi:10.1037/a0024291.

20. Stroop JR. Studies of interference in serial verbal reactions. J Exp Psychol. 1935; 18:643.

21. Braet C, Crombez G. Cognitive interference due to food cues in childhood obesity. J Clin Child Adolesc. 2003;32:32-9. doi:10.1207/S15374424JCCP3201 04.

22. Wenzlaff RM, Stultz CH. A new method of assessing attentional bias in depression. Washington, DC: In Meeting of the American Psychological Society; 1998.

23. Soetens B, Braet C. Information processing of food cues in overweight and normal weight adolescents. Brit J Health Psych. 2007;12:285-304. doi:10.1348/135910706X107604.

24. Werthmann J, Jansen A, Vreugdenhil ACE, et al. Food through the child's eye: an eye-tracking study on attentional bias for food in healthy-weight children and children with obesity. Health Psychol. 2015;34:1123-32. doi:10.1037/hea0000225.

25. Theeuwes J, Atchley P, Kramer AF. Attentional control within 3-D space. J Exp Psychol-Hum Percept Perform. 1998;24:1476.

26. Junghans AF, Hooge IT, Maas J, et al. Unadulterated — children and adults' visual attention to healthy and unhealthy food. Eat Behav. 2015;17:90-3

27. Weller RE, Cook EW, Avsar KB, et al. Obese women show greater delay discounting than healthy-weight women. Appetite. 2008;51: 563-9.

28. Gunstad J, Paul RH, Cohen RA, et al. Elevated body mass index is associated with executive dysfunction in otherwise healthy adults. Compr Psychiat. 2007;48:57-61.

29. Cserjési R, Luminet O, Poncelet A-S, et al. Altered executive function in obesity. Exploration of the role of affective states on cognitive abilities. Appetite. 2009;52:535-9. doi:10.1016/j. appet.2009.01.003.
30. Nederkoorn C, Smulders FTY, Havermans RC, et al. Impulsivity in obese women. Appetite. 2006;47:253-6. doi:10.1016/j. appet.2006.05.008.

31. Mostofsky SH, Simmonds DJ. Response inhibition and response selection: two sides of the same coin. J Cognitive Neurosci. 2008;20:751-61.

32. Fillmore MT, Rush CR. Polydrug abusers display impaired discrimination-reversal learning in a model of behavioural control. J Psychopharmacol. 2006;20:24-32.

33. Logan GD. On the ability to inhibit thought and action: a users' guide to the stop signal paradigm. 1994.

34. Mazur JE. An adjusting procedure for studying delayed reinforcement. Commons ML, Mazur JE, Nevin JA; 1987:55-73.

35. Mischel W, Ebbesen EB, Raskoff ZA. Cognitive and attentional mechanisms in delay of gratification. J Pers Soc Psychol. 1972;21:204.

36. Robbins TW, Weinberger D, Taylor JG, Morris RG. Dissociating executive functions of the prefrontal cortex [and discussion]. Phil Trans R Soc B. 1996;351:1463-71.

$37 . \bullet$ Casey B. Beyond simple models of self-control to circuit-based accounts of adolescent behavior. Annu Rev Psychol. 2015;66: 295-319. A comprehensive review which discusses the effect of developing brain circuitry in adolescents on risky behavior and self-control.

38. Barkin SL. The relationship between executive function and obesity in children and adolescents: a systematic literature review. J Obes. 2013;2013.

39. Braet C, Claus L, Verbeken S, et al. Impulsivity in overweight children. Eur Chil Adoles Psy. 2007;16:473-83. doi:10.1007/s00787007-0623-2.

40. Cserjési $\mathrm{R}$, Molnár $\mathrm{D}$, Luminet $\mathrm{O}$, et al. Is there any relationship between obesity and mental flexibility in children? Appetite. 2007;49:675-8. doi:10.1016/j.appet.2007.04.001.

41. Schlam TR, Wilson NL, Shoda Y, et al. Preschoolers' delay of gratification predicts their body mass 30 years later. J Pediatr. 2012. doi:10.1016/j.jpeds.2012.06.049.

42. Green L, Myerson J, Ostaszewski P. Discounting of delayed rewards across the life span: age differences in individual discounting functions. Behav Process. 1999;46:89-96. doi:10.1016/S03766357(99)00021-2.

43. Smeets PA, Charbonnier L, van Meer F, et al. Food-induced brain responses and eating behaviour. P Nutr Soc. 2012;71:511-20.

44. Huttenlocher PR, Dabholkar AS. Regional differences in synaptogenesis in human cerebral cortex. J Comp Neurol. 1997;387:167-78.

45. Sowell ER, Thompson PM, Holmes CJ, et al. In vivo evidence for post-adolescent brain maturation in frontal and striatal regions. Nat Neurosci. 1999;2:859-61.

46. Giedd JN, Blumenthal J, Jeffries NO, et al. Brain development during childhood and adolescence: a longitudinal MRI study. Nat Neurosci. 1999;2:861-3.

47. Booth JR, Burman DD, Meyer JR, et al. Neural development of selective attention and response inhibition. Neuroimage. 2003;20: $737-51$

48. Watanabe J, Sugiura M, Sato K, et al. The human prefrontal and parietal association cortices are involved in NO-GO performances: an event-related fMRI study. Neuroimage. 2002;17:1207-16.

49. Sowell ER, Peterson BS, Thompson PM, et al. Mapping cortical change across the human life span. Nat Neurosci. 2003;6:309-15.

50. Van der Laan LN, De Ridder DTD, Viergever MA, et al. The first taste is always with the eyes: a meta-analysis on the neural correlates of processing visual food cues. Neuroimage. 2011;55:296303. doi:10.1016/j.neuroimage.2010.11.055.

51. Yokum S, Ng J, Stice E. Attentional bias to food images associated with elevated weight and future weight gain: an fMRI study. Obesity. 2011;19:1775-83. doi:10.1038/oby.2011.168. 
52. Demos KE, Heatherton TF, Kelley WM. Individual differences in nucleus accumbens activity to food and sexual images predict weight gain and sexual behavior. J Neurosci. 2012;32:5549-52.

53. Van der Laan LN, De Ridder DTD, Viergever MA, et al. Appearance matters: neural correlates of food choice and packaging aesthetics. PLoS One. 2012;7, e41738. doi:10.1371/journal. pone. 0041738 .

54. Mehta S, Melhorn SJ, Smeraglio A, et al. Regional brain response to visual food cues is a marker of satiety that predicts food choice. Am J Clin Nutr. 2012. doi:10.3945/ajcn.112.042341.

55. Lawrence NS, Hinton EC, Parkinson JA, et al. Nucleus accumbens response to food cues predicts subsequent snack consumption in women and increased body mass index in those with reduced selfcontrol. Neuroimage. 2012;63:415-22. doi:10.1016/j. neuroimage.2012.06.070.

56. Killgore W, Weber M, Schwab Z, et al. Cortico-limbic responsiveness to high-calorie food images predicts weight status among women. Int J Obes. 2013;37:1435-42.

57. Murdaugh DL, Cox JE, Cook III EW, et al. fMRI reactivity to highcalorie food pictures predicts short-and long-term outcome in a weight-loss program. Neuroimage. 2012;59:2709-21.

58. Dagher A. Functional brain imaging of appetite. Trends Endocrin Met. 2012;23:250-60

59. Schachter S. Obesity and Eating Science. 1968;161:751-6. doi:10.1126/science.161.3843.751.

60. Brooks SJ, Cedernaes J, Schiöth HB. Increased prefrontal and parahippocampal activation with reduced dorsolateral prefrontal and insular cortex activation to food images in obesity: a metaanalysis of fMRI studies. PLoS One. 2013;8, e60393. An activation likelihood estimation meta-analysis on the neural correlates of food cue reactivity in obese compared to normalweight individuals.

61. Kennedy J, Dimitropoulos A. Influence of feeding state on neurofunctional differences between individuals who are obese and normal weight: a meta-analysis of neuroimaging studies. Appetite. 2014;75:103-9.

62. van Meer F, van der Laan LN, Adan RAH, et al. What you see is what you eat: an ALE meta-analysis of the neural correlates of food viewing in children and adolescents. Neuroimage. 2015;104:35-43. doi:10.1016/j.neuroimage.2014.09.069. An activation likelihood estimation meta-analysis on the neural correlates of food cue reactivity in children compared to adults.

63. Davids $\mathrm{S}$, Lauffer $\mathrm{H}$, Thoms $\mathrm{K}$, et al. Increased dorsolateral prefrontal cortex activation in obese children during observation of food stimuli. Int J Obes. 2010;34:94-104.

64. Bruce AS, Holsen LM, Chambers RJ, et al. Obese children show hyperactivation to food pictures in brain networks linked to motivation, reward and cognitive control. Int J Obes. 2010;34:1494500 .

65. Stice E, Spoor S, Bohon C, et al. Relation of reward from food intake and anticipated food intake to obesity: a functional magnetic resonance imaging study. J Abnorm Psychol. 2008;117:924-35. doi:10.1037/a0013600.

66. Grabenhorst F, Schulte FP, Maderwald S, et al. Food labels promote healthy choices by a decision bias in the amygdala. Neuroimage. 2013;74:152-63.

67. van der Laan LN, De Ridder DT, Charbonnier L, et al. Sweet lies: neural, visual, and behavioral measures reveal a lack of self-control conflict during food choice in weight-concerned women. Front Behav Neurosci. 2014;8.

68. van der Laan LN, de Ridder DT, Viergever MA, et al. Activation in inhibitory brain regions during food choice correlates with temptation strength and self-regulatory success in weightconcerned women. Front Neurosci. 2014;8.

69. Charbonnier L, van der Laan LN, Viergever MA, et al. Functional MRI of challenging food choices: forced choice between equally liked high- and low-calorie foods in the absence of hunger. PLoS One. 2015;10, e0131727. doi:10.1371/journal.pone.0131727.

70. Litt A, Plassmann H, Shiv B, et al. Dissociating valuation and saliency signals during decision-making. Cereb Cortex. 2011;21: 95-102. doi:10.1093/cercor/bhq065.

71. Lim S-L, O'Doherty JP, Rangel A. The decision value computations in the vmPFC and striatum use a relative value code that is guided by visual attention. J Neurosci. 2011;31:13214-23. doi:10.1523/jneurosci.1246-11.2011.

72. Hare TA, Camerer CF, Rangel A. Self-control in decision-making involves modulation of the vmPFC valuation system. Science. 2009;324:646-8. doi:10.1126/science.1168450.

73. Hare TA, Malmaud J, Rangel A. Focusing attention on the health aspects of foods changes value signals in vmPFC and improves dietary choice. J Neurosci. 2011;31:11077-87. doi:10.1523/jneurosci.6383-10.2011.

74. Chib VS, Rangel A, Shimojo S, et al. Evidence for a common representation of decision values for dissimilar goods in human ventromedial prefrontal cortex. J Neurosci. 2009;29:12315-20. doi:10.1523/jneurosci.2575-09.2009.

75. Plassmann H, O’Doherty JP, Rangel A. Appetitive and aversive goal values are encoded in the medial orbitofrontal cortex at the time of decision making. J Neurosci. 2010;30:10799-808. doi:10.1523/jneurosci.0788-10.2010.

76. Plassmann H, O'Doherty J, Rangel A. Orbitofrontal cortex encodes willingness to pay in everyday economic transactions. J Neurosci. 2007;27:9984-8. doi:10.1523/jneurosci.2131-07.2007.

77. Hare TA, O'Doherty J, Camerer CF, et al. Dissociating the role of the orbitofrontal cortex and the striatum in the computation of goal values and prediction errors. J Neurosci. 2008;28:5623-30. doi:10.1523/jneurosci.1309-08.2008.

78. Linder NS, Uhl G, Fliessbach K, et al. Organic labeling influences food valuation and choice. Neuroimage. 2010;53:215-20. doi:10.1016/j.neuroimage.2010.05.077.

79. Bettman JR, Luce MF, Payne JW. Constructive consumer choice processes. J Consum Res. 1998;25:187-217.

$80 . \bullet$ Rangel A. Regulation of dietary choice by the decision-making circuitry. Nat Neurosci. 2013;16:1717-24. doi:10.1038/nn.3561. A neuro-computational perspective on the brain systems that regulate food choice.

81. Kang MJ, Rangel A, Camus M, et al. Hypothetical and real choice differentially activate common valuation areas. J Neurosci. 2011;31:461-8. doi:10.1523/jneurosci.1583-10.2011.

82. Thorndike AN, Sonnenberg L, Riis J, et al. A 2-phase labeling and choice architecture intervention to improve healthy food and beverage choices. Am J Public Health. 2012;102: 527-33.

83. Enax L, Hu Y, Trautner P, Weber B. Nutrition labels influence value computation of food products in the ventromedial prefrontal cortex. Obesity. 2015;23:786-92. doi:10.1002/oby.21027. This study shows that attending to a traffic light nutrition label triggers neurobiological processes that resemble those utilized by successful dieters.

84. Barnard ND, Bush AI, Ceccarelli A, et al. Dietary and lifestyle guidelines for the prevention of Alzheimer's disease. Neurobiol Aging. 2014;35(2):S74-S8. doi:10.1016/j. neurobiolaging.2014.03.033. 